\section{(6) OPEN ACCESS}

\title{
Converting everolimus to mycophenolate mofetil ameliorated prolonged respiratory syncytial virus infection in a child after heart transplantation
}

\author{
Hidehiro Suginobe, Nobutoshi Nawa, Hidekazu Ishida, Shigetoyo Kogaki
}

Department of Paeditatrics,

Osaka University Graduate School of Medicine, Suita, Japan

Correspondence to Dr Shigetoyo Kogaki, skogaki@ped.med.osaka-u.ac.jp

Accepted 4 July 2017

\begin{abstract}
SUMMARY
In immunocompromised patients, respiratory syncytial virus (RSV) infections are known to be severe and prolonged, and have significant mortality and morbidity. However, little is known about the clinical courses and treatment strategy of RSV infection in heart transplant recipients. Here, we report a 6 -year-old female with heart transplantation who had exhibited prolonged respiratory symptoms and shedding of RSV. She had received everolimus as an immunosuppressant. As immunosuppressants could have been responsible for the prolonged activation of RSV, we converted everolimus to mycophenolate mofetil. After the conversion, RSV promptly disappeared, and her symptoms improved. We speculate that converting the immunosuppressant may be effective for prolonged RSV infection due to the different immunosuppressive mechanisms.
\end{abstract}

\section{BACKGROUND}

Respiratory syncytial virus (RSV) is the most common cause of morbidity and mortality of all respiratory virus infections affecting transplant recipients. ${ }^{12}$ Although there are some reports that described cases of lower respiratory RSV infection in patients with lung or bone marrow transplants, ${ }^{3}{ }^{4}$ the clinical features of RSV in patients with heart transplantation are less well characterised. ${ }^{35}$ Recipients of solid organ transplants are not as critically ill as those of lung or bone marrow transplants, but the extent of immunosuppression affects their clinical severity. ${ }^{6}$ The mortality can reach to $83 \%$ with RSV pneumonia infection in immunocompromised recipients ${ }^{6}$; therefore, treating RSV infection properly in immunocompromised patients is thought to be important. Palivizumab, inhaled or oral ribavirin (RBV) and intravenous immunoglobulin (IVIG) have been reported to be effective for RSV infection. ${ }^{7}$ However, the treatment strategy for RSV infection in immunocompromised patients has not been established and differs among institutions. ${ }^{7}$

Here, we report a case in which a paediatric heart-transplant recipient demonstrated prolonged RSV infection, and we propose that conversion of the immunosuppressive agent from everolimus to mycophenolate mofetil (MMF) may be an option for the treatment of compromised RSV infection.

\section{CASE PRESENTATION}

A 6-year-old girl who underwent heart transplantation at the age of 3 was admitted to our hospital because of recurrent fever, productive cough and rhinorrhea for 3 weeks.

She was born with congenital atrioventricular block and underwent pacemaker implantation as a newborn. She developed secondary dilated cardiomyopathy at the age of one. She needed orthotropic heart transplantation at the age of 3 because of severe heart failure associated with dilated cardiomyopathy.

At presentation, her blood pressure was $82 / 40 \mathrm{~mm} \mathrm{Hg}$, heart rate was regular at $100 \mathrm{bpm}$, respiratory rate was 42 breaths/min and body temperature was $38.0^{\circ} \mathrm{C}$. Peripheral oxygen saturation was 94\%. Auscultation revealed diffuse inspiratory crackles over both lungs. Her medications included tacrolimus $(0.25 \mathrm{mg} / \mathrm{kg})$, everolimus $(0.063 \mathrm{mg} / \mathrm{kg})$, famotidine and atenolol.

\section{INVESTIGATIONS}

Laboratory testing demonstrated a normal leucocyte count $\left(4620 / \mathrm{mm}^{3}\right)$ with a slightly elevated level of $\mathrm{C}$ reactive protein $(1.3 \mathrm{mg} / \mathrm{L})$ and elevated levels of KL-6 $(795 \mathrm{U} / \mathrm{mL})$, creatinine $(1.2 \mathrm{mg} / \mathrm{dL})$ and brain natriuretic peptide (BNP, $276 \mathrm{pg} / \mathrm{mL}$ ). She had a normal level of immunoglobulin (Ig) G (1479 mg/dL). Drug-induced lymphocyte stimulation test (DLST) for everolimus was negative. We could not measure the level of everolimus at that time.

Chest X-ray and pulmonary CT scan showed bilateral pulmonary infiltrates, mostly in the inferior lobes, as shown in figure 1A. Gallium scintigraphy revealed the accumulation of signals in the same location of the lungs, except for pulmonary lymph nodes. Bacterial cultures of blood and sputum were negative. Screening tests for Influenza virus, Cytomegalovirus, Epstein-Barr virus, Pneumocystis jirovecii, Mycoplasma pneumoniae and Mycobacterium tuberculosis complex were all negative. A rapid RSV antigen panel was positive, and we confirmed the diagnosis of lower respiratory RSV infection based on a positive RSV PCR test on her sputum.

\section{DIFFERENTIAL DIAGNOSIS}

The following differential diagnoses were considered: congestive heart failure, post-transplant lymphoproliferative disorders (PTLD), opportunistic infections in the lung and interstitial pneumonia (IP). 

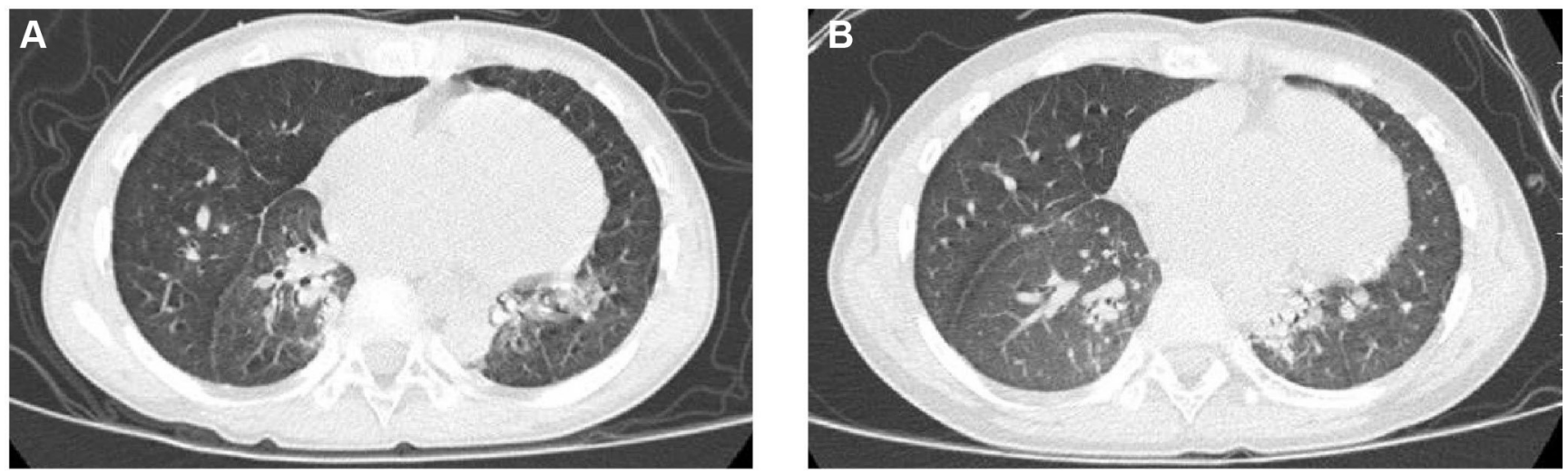

Figure 1 (A) Chest CT on admission, (B) chest CT 6 months after discharge.

Although the BNP level was higher than normal, repeated echocardiography exams exhibited normal ventricular contraction and no pericardial effusion. Cardiac catheterisation revealed that she had no haemodynamic exacerbation, and myocardial biopsy demonstrated no signs of acute rejection.

Children after heart transplantation have the risk of developing PTLD, but her symptoms were limited to respiratory organs, and gallium scintigraphy showed no abnormal accumulation in her systemic lymph nodes.

As she had a high fever and productive cough for several weeks and took immunosuppressants, we suspected that she had an opportunistic respiratory infection. However, repeated tests for P. jirovecii, M. pneumoniae, M. tuberculosis complex, and fungi were all negative.

As for IP, a CT scan revealed small localised damage to the lung interstitium and DLST for everolimus was negative. While we could not definitively exclude the possibility of everolimus-induced IP, we speculated that RSV was more likely responsible for her respiratory symptoms rather than IP.

\section{TREATMENT}

Her symptoms and positive RSV antigen panel reactions continued for 2 months despite supportive therapies, including antibiotics for the possible concomitant bacterial infections. On suspicion of prolonged RSV infection due to immunosuppressive therapy, we decided to switch everolimus to MMF. This conversion resulted in relatively prompt improvement of her respiratory symptoms without any rejection, and RSV antigen panel reactions and PCR testing became negative within 1 month. The values of KL- 6 gradually decreased after immunosuppressant conversion. The value of KL-6 on discharge was $182 \mathrm{U} / \mathrm{mL}$

Although tacrolimus levels were predicted to be unstable because tacrolimus and everolimus are thought to be metabolised by similar enzymes, such as CYP3A4, the levels were only slightly elevated just after the conversion and spontaneously reached the target range (6 to $8 \mathrm{ng} / \mathrm{mL}$ ), thus we did not need to adjust the dose of tacrolimus.

\section{OUTCOME AND FOLLOW-UP}

She was discharged on day 104 after admission. A follow-up CT scan was performed 6 months after the discharge and demonstrated significant resolution of the previous bilateral pulmonary infiltration, as shown in figure $1 \mathrm{~B}$. She had no recurrent RSV infections and no rejection 8 years afterwards.

\section{DISCUSSION}

RSV is a seasonal respiratory virus, usually causing upper and lower respiratory tract infections in younger children. Moreover, RSV causes severe respiratory disease, especially in premature infants, children with congenital heart disease and immunocompromised patients. ${ }^{12}$ There are some reports on prolonged RSV infections in patients after lung or bone marrow transplantation $^{34}$ but few on patients after heart transplantation. ${ }^{3-5}$

In our 6-year-old patient, her respiratory symptoms lasted more than 2 months. Although the investigation was thorough, we could not find any evidence suggestive of causes other than RSV infection. We should keep in mind that prolonged RSV infections can occur in older children with weakened immune systems such as post-heart transplantation.

The human immune response to RSV infection is mainly comprised of neutrophils, dendritic cells and gamma interferon. ${ }^{8}$ RSV infection causes a strong response of neutrophils, which is correlated with its clinical severity. Dendritic cells migrate to the lungs and work as primary antigen-presenting cells, and CD8+ T-cell response follows, contributing to viral clearance. The Th1 response produces gamma interferon, which also has a protective role for RSV infection. ${ }^{8}$

Dendritic cells, which initiate T-cell mediated cellular immunity, may be responsible for resolution of RSV infection in animal models. ${ }^{9}$ Two major types of dendritic cells have been discovered and termed conventional and plasmacytoid dendritic cells (pDCs). The pDCs play important roles, particularly in enhancing RSV clearance. ${ }^{10}$ A recent study suggests that the mammalian target of rapamycin (mTOR) pathway regulates DC differentiation and induces DC activation. ${ }^{11}$ Everolimus works as an mTOR inhibitor and inhibits this pathway, which may be related to her prolonged RSV infection. Converting everolimus to MMF leads to restoring mTOR signalling and DC activation and may have contributed to the resolution of prolonged RSV infection in our case. We think this case report is important in that DCs could have a central role in the immune mechanism for RSV clearance. Weng et al reported that a low level of pDCs in peripheral blood indicates the development of RSV lower respiratory infections, ${ }^{12}$ which also supports our hypothesis. Effects on DCs by MMF have not been thoroughly investigated so far.

Palivizumab, oral and inhaled RBV and IVIG are used for treating RSV infections in immunocompromised patients, ${ }^{7}$ and a combination of these drugs (and/or palivizumab, and/or RBV and/or IVIG) is beneficial in inhibiting progression to lower respiratory infection and mortality. ${ }^{7}$ The use of palivizumab and RBV are off-label use for the treatment of RSV infection in 
Japan, and we did not use IVIG due to her normal serum IgG level. Thus, we changed everolimus considering its suppressive effect on DCs; however, a combination of these drugs could be tried before changing immunosuppressants. There is no established treatment strategy for RSV infection in immunocompromised patients, and trials of RSV treatments for immunocompromised patients are needed to verify the efficacy of those drugs. We think this case report is unique in demonstrating that changing immunosuppressants could be an optional treatment for prolonged and severe RSV infection after standard therapy.

Everolimus is an inhibitor of mTOR, ${ }^{13}$ and MMF is an inhibitor of inosine monophosphate dehydrogenase,${ }^{14}$ both of which are used in heart transplant recipients. With respect to international trends in the use of maintenance immunosuppressive agents, combinations of tacrolimus and MMF with or without steroids were most common (52\%), followed by cyclosporine and MMF with or without steroids (26\%). ${ }^{15}$ The use of mTOR inhibitors remained low at 1 year ( $8 \%$ of patients) and 5 years (19\% of patients) of follow-up; however, they are becoming preferentially used in recent years for reduced progression of renal insufficiency and allograft vasculopathy. ${ }^{15}$ IP has been reported as a side effect of everolimus, ${ }^{16}$ but in our case, there was no strong evidence of diffuse damage to the lung interstitium on her chest CT. Although her KL-6, which is a biomarker of IP, ${ }^{17}$ was high on admission, KL-6 is also reported to be high in RSV bronchiolitis. ${ }^{18}$ As mentioned above, we thought the high value of KL-6 mainly reflected RSV infection, not IP. RSV antigen tests by rapid antigen test and PCR became negative after converting the immunosuppressant, which also supports our speculation. We could have done a provocation test, which is a more reliable method, to differentiate it from everolimus-induced IP. ${ }^{19}$

Our study has a number of limitations. Changing immunosuppressants has the risk of making their concentrations unstable and causing graft rejection. Furthermore, everolimus is advantageous in slowing progression of cardiac allograft vasculopathy and being renal protective.

In this case report, we presented a heart transplant patient receiving immunosuppressants who exhibited severe prolonged RSV infection and demonstrated that changing everolimus to MMF may be another treatment option for RSV infection. Future studies are needed to clarify the immunological responses

\section{Learning points}

- Respiratory syncytial virus (RSV) infection in older children with heart transplantation may become exacerbated and last for a long period.

- If RSV infection is prolonged despite comprehensive therapy, change of immunosuppressant regimen may be considered with careful monitoring for rejection.

- Future studies are necessary to clarify the pathobiology of RSV infection under weakened immune systems and to establish clinical guidelines for the management of heart transplant recipients with RSV infection. to RSV infection and to develop a treatment strategy in heart transplant recipients.

Contributors Wrote the paper: SH, NN. Reviewed and finalised the manuscript: $\mathrm{IH}, \mathrm{KS}$.

Competing interests None declared.

Patient consent Obtained from guardian.

Provenance and peer review Not commissioned; externally peer reviewed.

Open Access This is an Open Access article distributed in accordance with the Creative Commons Attribution Non Commercial (CC BY-NC 4.0) license, which permits others to distribute, remix, adapt, build upon this work non-commercially, and license their derivative works on different terms, provided the original work is properly cited and the use is non-commercial. See: http://creativecommons.org/ licenses/by-nc/4.0/

(C) BMJ Publishing Group Ltd (unless otherwise stated in the text of the article) 2017. All rights reserved. No commercial use is permitted unless otherwise expressly granted.

\section{REFERENCES}

1 Falsey AR, Walsh EE. Respiratory syncytial virus infection in adults. Clin Microbiol Rev 2000;13:371-84.

2 Kumar D, Humar A. Respiratory viral infections in transplant and oncology patients. Infect Dis Clin North Am 2010;24:395-412.

3 Pilie P, Werbel WA, Riddell J, et al. Adult patients with respiratory syncytial virus infection: impact of solid organ and hematopoietic stem cell transplantation on outcomes. Transpl Infect Dis 2015;17:551-7.

4 Lo MS, Lee GM, Gunawardane N, et al. The impact of RSV, adenovirus, influenza, and parainfluenza infection in pediatric patients receiving stem cell transplant, solid organ transplant, or cancer chemotherapy. Pediatr Transplant 2013;17:133-43.

5 Grodin JL, Wu KS, Kitchell EE, et al. Respiratory syncytial virus pneumonia treated with lower-dose palivizumab in a heart transplant recipient. Case Rep Cardiol 2012:2012:723407.

6 Whimbey E, Couch RB, Englund JA, et al. Respiratory syncytial virus pneumonia in hospitalized adult patients with leukemia. Clin Infect Dis 1995;21:376-9.

7 Beaird $\mathrm{OE}$, Freifeld A, Ison MG, et al. Current practices for treatment of respiratory syncytial virus and other non-influenza respiratory viruses in high-risk patient populations: a survey of institutions in the Midwestern Respiratory Virus Collaborative . Transpl Infect Dis 2016;18:210-5.

8 Russell CD, Unger SA, Walton M, et al. The Human Immune Response to Respiratory Syncytial Virus Infection. Clin Microbiol Rev 2017;30:481-502.

9 Ogra PL. Respiratory syncytial virus: the virus, the disease and the immune response. Paediatr Respir Rev 2004;5(Suppl A):S119-S126.

10 Wang H, Peters N, Schwarze J. Plasmacytoid dendritic cells limit viral replication, pulmonary inflammation, and airway hyperresponsiveness in respiratory syncytial virus infection. J Immunol 2006; 177:6263-70.

11 Sukhbaatar N, Hengstschläger M, Weichhart T. mTOR-Mediated Regulation of Dendritic Cell Differentiation and Function. Trends Immunol 2016;37:778-89.

12 Weng K, Zhang J, Mei X, et al. Lower number of plasmacytoid dendritic cells in peripheral blood of children with bronchiolitis following respiratory syncytial virus infection. Influenza Other Respir Viruses 2014:8:469-73.

13 Neuhaus P, Klupp J, Langrehr JM. mTOR inhibitors: an overview. Liver Transp/ 2001:7:473-84.

14 Sievers TM, Rossi SJ, Ghobrial RM, et al. Mycophenolate mofetil. Pharmacotherapy 1997:17:1178-97.

15 Lund LH, Edwards LB, Dipchand Al, et al. The Registry of the International Society for Heart and Lung Transplantation: Thirty-third Adult Heart Transplantation Report-2016; Focus Theme: Primary Diagnostic Indications for Transplant. J Heart Lung Transplant 2016;35:1158-69.

16 David S, Kümpers P, Shin $\mathrm{H}$, et al. Everolimus-associated interstitial pneumonitis in a patient with a heart transplant. Nephrol Dial Transplant 2007;22:3363-4.

17 Sun AP, Ohtsuki Y, Fujita J, et al. Immunohistochemical characterisation of pulmonary hyaline membrane in various types of interstitial pneumonia. Pathology 2003:35:120-4.

18 Kawasaki Y, Aoyagi Y, Abe Y, et al. Serum KL-6 levels as a biomarker of lung injury in respiratory syncytial virus bronchiolitis. J Med Virol 2009;81:2104-8.

19 Matsuno O, Okubo T, Hiroshige S, et al. Drug-induced lymphocyte stimulation test is not useful for the diagnosis of drug-induced pneumonia. Tohoku J Exp Med 2007:212:49-53. 
Copyright 2017 BMJ Publishing Group. All rights reserved. For permission to reuse any of this content visit http://group.bmj.com/group/rights-licensing/permissions.

BMJ Case Report Fellows may re-use this article for personal use and teaching without any further permission.

Become a Fellow of BMJ Case Reports today and you can:

- Submit as many cases as you like

- Enjoy fast sympathetic peer review and rapid publication of accepted articles

- Access all the published articles

- Re-use any of the published material for personal use and teaching without further permission

For information on Institutional Fellowships contact consortiasales@bmjgroup.com

Visit casereports.bmj.com for more articles like this and to become a Fellow 